\title{
SEDIMENTOLOGIA DE LAS FACIES DETRITICAS DE LA UNIDAD INTERMEDIA DEL MIOCENO AL SUR Y ESTE DE MADRID
}

\author{
A. Lomoschitz, J. P. Calvo y. S. Ordóñez (*)
}

\begin{abstract}
Resumen
Dentro de los niveles correspondientes a la Unidad Intermedia del Mioceno en las áreas al este y sur de Madrid, los depósitos de arenas micáceas constituyen un término característico y ampliamente repartido en las facies "transicionales" entre depósitos arcósicos asociados a los bordes de cuenca y depósitos carbonatados-lutíticos de posiciones más centrales.

La particularidad de las arenas situadas en esta posición transicional reside en el alto porcentaje en peso $\mathrm{y} / \mathrm{o}$ en número de granos de micas biotitas. Dichas arenas aparecen bien representadas en términos correspondientes a dos sistemas deposicionales diferenciados. Por una parte, se han estudiado estas arenas en el área de Alcalá de Henares y Torrejón de Ardoz (Canteras de La Granja), presentando aquí los niveles arenosos rasgos propios de depósitos "sheet flood" a partir de cursos efímeros bien representados hacia el noreste. En el área de Madrid, y desde esta zona hasta Esquivias, las arenas micáceas se reconocen en secuencias de relleno de canal, "sheet floods", así como en secuencias deltaicas de escaso desarrollo. Se presentan, por último, una serie de consideraciones relativas a las distribuciones granulométricas de las arenas micáceas sobre la base de las correcciones derivadas de la forma de los granos de mica, analizándose sus implicaciones en cuanto a la interpretación hidrodinámica de estos niveles arenosos.

Palabras clave: Sedimentación continental, arenas micáceas, biotita, texturas, Mioceno, cuenca de Madrid.
\end{abstract}

\section{Abstract}

Micaceous sandstone beds form a characteristic lithofacies of the Middle Miocene deposits in the north-eastern side of the Madrid Basin. They are arranged in a transitional position between arkosic marginal deposits and central lutite-carbonate sediments in the basin.

Biotite mica grains account for more than half of the total number grains in most of the sandstone beds. Also, mica grains commonly reach up 20-30 percent of the sample weight. Micaceous sandstones occur in two different depositional systems. They were deposited as sheet floods and moderately sinuous streams in the Alcalá-Torrejón anea (medial to distal sequences of an alluvial-playa complex coming from the NE). Near Madrid and to the south of the city (Pinto-Esquivias area), micaceous sandstones occur as channel fills, sheet-flood deposits and small deltaic sequences. They were derived from arkosic alluvial fans.

Some considerations about the peculiarities of the micaceous sandstones have been made in order to envisage corrections on grain-size distributions. Presumed corrections are derived from high mica contents and flattened shapes of these grains.

KEY wORDs: Continental sedimentation, micaceous sandstones, biotite, textures, Miocene, Madrid basin.

\section{Introducción}

El presente trabajo tiene como objeto la caracterización sedimentológica de los niveles terrígenos en facies de arenas micáceas incluidas dentro de la Unidad Intermedia del Mioceno en las áreas este y sur de Madrid, desde los alrededores de Esquivias hasta Alcalá de Henares. La definición con carácter general de la Unidad Intermedia para la sucesión miocena de la cuenca de Madrid ha sido recientemente formulada por diversos autores (Alberdi et al., 1983; Ordóñez et al., 1981; Calvo et al., 1984; Hoyos et al.,

(*) Dpto. de Petrología y Geoquímica. Facultad de Geológicas. Univ. Complutense. 28040 Madrid. 
1985; Junco y Calvo, 1984). Bajo este término se incluye el conjunto sedimentario, aflorante a lo largo de la mayor parte de la cuenca, que queda comprendido entre los depósitos evaporíticos correspondientes a la Unidad Inferior del Mioceno o Unidad Salina (García del Cura, 1979) y la Unidad superior (Alberdi et al., 1983; Junco y Calvo, 1984), cuya base viene definida por los depósitos terrígenos de la «red fluvial intramiocena» de Carro y Capote (1968).
El límite inferior de la Unidad Intermedia del Mioceno queda definido por una discontinuidad que se detecta por un fuerte cambio en la naturaleza litológica y geoquímica de los depósitos, por el desarrollo en algunas áreas de una superficie de erosión y karstificación sobre los yesos infrayacentes (Calvo et al., 1984) y, en general, por una penetración más profunda de depósitos terrígenos hacia el centro de la cuenca (Torres et al., 1984; Junco y Calvo, 1984).

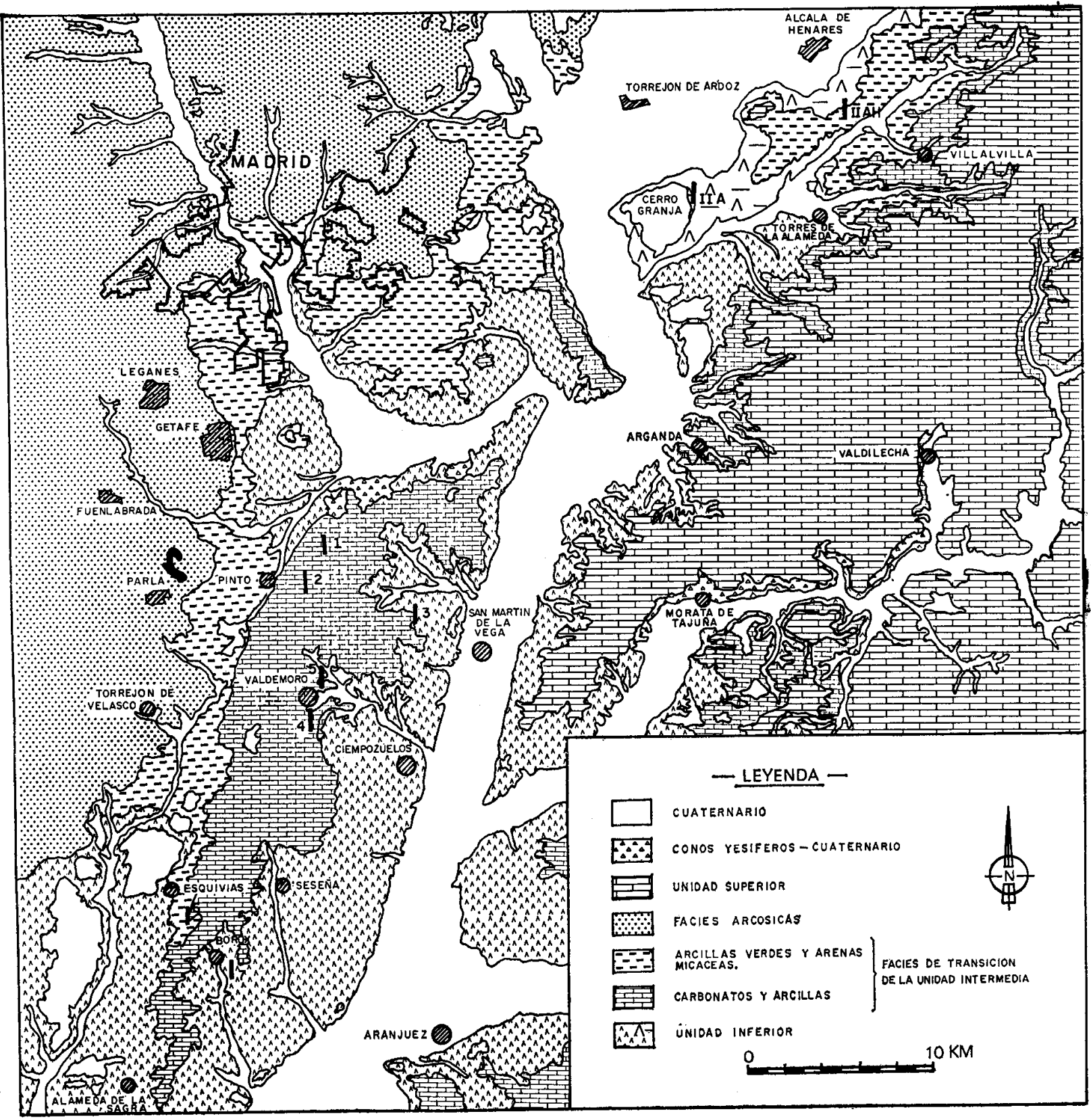

Fig. 1.-Esquema geológico de la zona estudiada con situación de las columnas analizadas. Esquema basado en Carro y Capote (1968), Vegas et al. (1975), San José (1975) y Calvo et al. (1984). 
Litológicamente la Unidad Intermedia aparece constituida por una variedad de depósitos entre los que destacan yesos detríticos (Megías et al., 1982) y carbonatos en las partes centrales de la cuenca, alternancias de lutitas y carbonatos con niveles de arenas finas bordeando esas áreas centrales y, por último, depósitos netamente arcósicos con granulometrías progresivamente más gruesas en los bordes. De acuerdo con esta disposición centrípeta de facies quedaría delimitado en una posición intermedia un conjunto carbonático y carbonático-lutítico que ha sido descrito como «facies de transición» (Riba, 1957) o como «Serie Blanca» (Alía, 1960; Alía et al., 1973).

La distribución espacial de estos depósitos, en el área que nos ocupa ha sido expresada cartográficamente por diversos autores (Carro y Capote, 1968; Vegas et al., 1975; San José, 1975). En la figura 1 se presenta un esquema cartográfico donde aparecen representadas las facies de transición de la Unidad Intermedia de acuerdo con los criterios señalados más, arriba. Dicho esquema se ha construido sobre la base, con ligeras modificaciones, de las cartografías citadas, así como sobre los datos obtenidos en un reciente estudio geológico del área de Madrid (Calvo et al., 1984).

El análisis presentado en este trabajo se,centra en el conjunto definido como Arcillas verdes y Arenas micáceas dentro de las Facies de Transición de la Unidad Intermedia. Dicho conjunto puede ser seguido (fig. 1) a lo largo de una amplia franja desde Esquivias-Borox hasta el sur de Madrid y vuelve a estar bien representado en el área de Torrejón de Ardoz-Alcalá de Henares. Desde un punto de vista litológico dominan en este conjunto los niveles lutíticos, generalmente, con tonalidades verdosas, intercalando cada vez con más frecuencia hacia el sur y este depósitos carbonáticos. Los procesos de silicificación son abundantes en algunos niveles. Dentro de esta asociación de litofacies los niveles de arenas micáceas constituyen un término peculiar tanto por las carcterísticas propias, de los depósitos como por la continuidad con la que aparecen a lo largo de toda la zona estudiada. Las primeras referencias sobre estas arenas, se deben a Royo Gómez (1929), quien en la memoria de la hoja geológica de Madrid las cita bajo el término de «arenas glauconíferas» en función del tono verde oscuro de las micas. Desde entonces las referencias a estos depósitos arenosos quedan únicamente a nivel de mera mención en las descripciones litoestratigráficas de la zona y son en cualquier caso nulos los trabajos específicos sobre ellos.

La, peculiaridad de la litofacies arenosa reside en el alto contenido en micas oscuras que presenta, contenido que se mantiene con escasa variación en los niveles arenosos que caracterizan la franja de depósitos entre los carbonatos más centrales y las facies terrígenas de borde. Es propósito de este estudio el análisis sedimentológico de detalle de los niveles de arenas micáceas con objeto de caracterizar el sistema deposicional en que se incluyen. Asimismo se efectúa un análisis específico desde, el punto de vista textural y mineralógico de estas arenas con objeto de establecer las implicaciones que en la interpretación hidrodinámica,pueden tener los altos porcentajes en mica señalados. Para ello se han estudiado un total de 18 secciones, generalmente parciales, de la Unidad Intermedia entre Esquivias y Alcalá de Henares (fig. 1), con muestreo especialmente dirigido a los niveles arenosos. En estos se ha realizado un estudio, textural y mineralógico completo, que incluye la separación magnética de micas y el montaje de granos en plástico. El tratamiento de datos texturales y de frecuencia de facies ha sido llevado a cabo mediante programas sencillos en lenguaje Basic, excepto en el Análisis Factorial, para el que se empleó un programa Varimax en lenguaje Fortran.

De acuerdo con las asociaciones de facies observadas pueden diferenciarse dos sectores dentro del área estudiada. El más septentrional corresponde a la zona de Alcalá de Henares-Torrejón de Ardoz, con Loeches como punto representativo del cambio lateral,de facies hacia depósitos predominantemente carbonatados. El otro sector incluye el área de $\mathrm{Ma}$ drid, extendiéndose por el sur hasta Esquivias, en la provincia de Toledo.

\section{Sector de Alcalá-Torrejón}

El límite inferior de la Unidad Intermedia en este sector queda definido por el fuerte incremento de niveles terrígenos gruesos litareníticos sobre el conjunto, a grandes rasgos homogéneo, conocido como Arcillas de Alcalá. Este quedaría integrado dentro de la Formación o Unidad Alcalá (López Vera, 1975; Villarroya, 1983). Dicho incremento de la presencia de niveles arenosos en la vertical es apreciable a lo largo de todo el frente situado al sur de Alcalá de $\mathrm{He}$ nares (Carro y Capote, 1968), por ejemplo en la subida al Gurugú o en la falda del Cerro del Viso. Algo más al sureste, en el Cerro de la Granja, la entrada de terrígenes más gruesos viene representada por varios niveles de arenas micáceas sobre las arcillas. Una asociación mixta de litarenitas y arenas micáceas aparece bien expuesta en diversas canteras del área de Torres de la Alameda. Por último, en los alrededores de Loeches, todos estos términos arenosos están ausentes, quedando la sucesión compuesta por lutitas y carbonatos.

El estudio de los niveles arenosos se ha realizado a partir de una sección bastante completa en la subida al Gurugú (carretera de Alcalá de Henares a Villalba) y del análisis detallado de un gran número de secciones en las canteras del Cerro Granja. Un esquema de la posición relativa y de las características que presentan estas secciones se presenta en la figura 2. La leyenda correspondiente a esta figura así como a la figura 10 , se presenta en la figura 3 .

La sección levantada en Alcalá de Henares (IIAH en la fig. 1) presenta en su base niveles correspondientes al conjunto arcilloso arriba señalado. Entre las arcillas se intercalan algunas pasadas muy finas de arenas micáceas y muestran, asimismo, un cierto desarrollo de carbonataciones. Estas características cambian drásticamente a los 14,5 metros de la sucesión, dando paso al predominio de niveles arenosos. Estos, en bancos generalmente de orden métrico, constituyen 


\section{ALCALA DE HENARES}
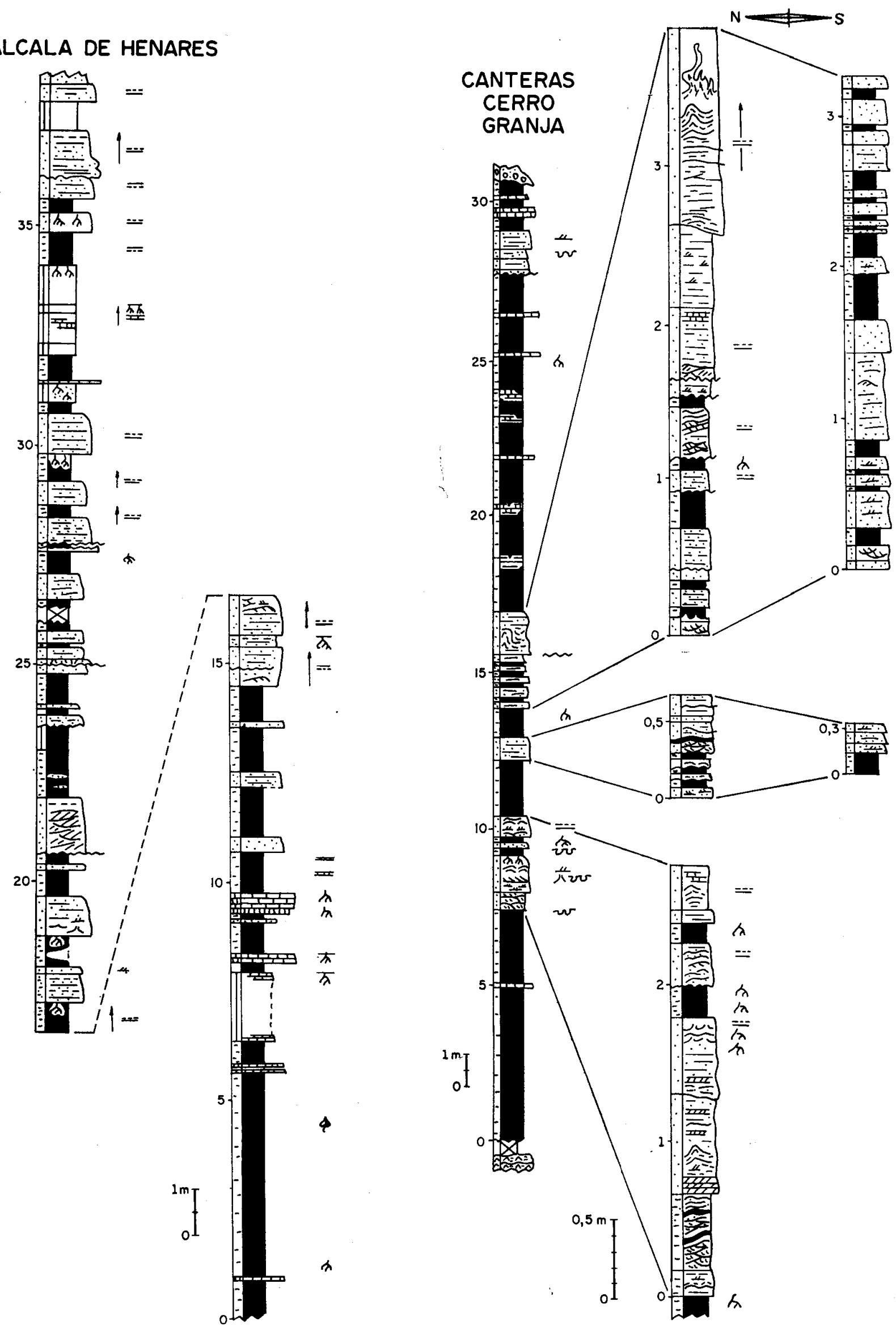

Fig. 2.-Principales secciones estudiadas en el sector de Alcalá de Henares-Torrejón de Ardoz. Leyenda de las columnas en la figura 3. 
el $65 \%$ de la serie y alternan con lutitas algo arenosas rojizas. Composicionalmente se reconocen dos facies mayores do arenas que, a su vez, son caracterizadas por el tamaño de grano, tipo de estructuras sedimentarias y tonalidad. La facies predominante corresponde a arenas cuarzo-feldespáticas con fragmentos de roca (litarenitas feldespáticas o arcosas litareníticas), de tamaño medio a grueso $(\overline{\mathrm{X}}=3$ phi, $\mathrm{s}=0.85$, centil $=0.5 \mathrm{~mm}$. y mediana $=0.15 \mathrm{~mm}$.), tonos pardos a rojizosy con un contenido medio en minerales pesados del $1.5 \%$ sobre el total de la muestra. El espectro de minerales pesados lo constituyen turmalina, granate, hematites $y$, como accesorios, distena, apatito y micas. Subordinada en la sección de Alcalá, aunque, como veremos, más frecuente hacia el sur y sureste, la facies de arenas micáceas es también de naturaleza cuarzo-feldespática, aunque de textura más fina y tonalidad verdosa característica. Su contenido en minerales pesados es muy reducido y se restringe, aparte de las micas, a la asociación turmalina-circón.

\section{LEYENDA DE LAS COLUMNAS}

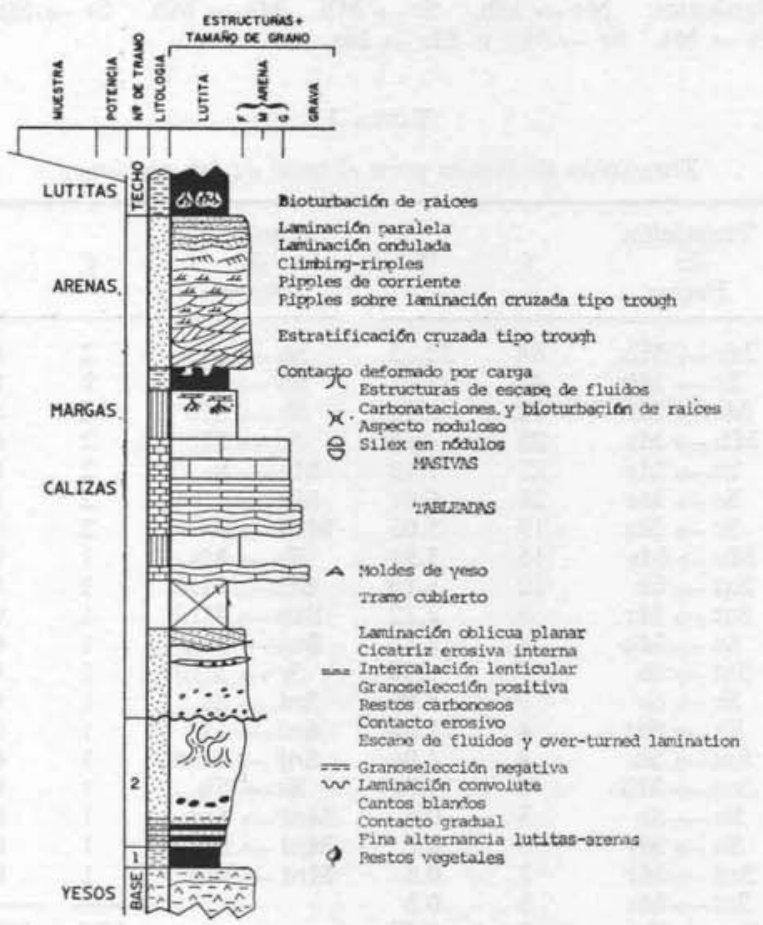

Fig. 3.-Leyenda de las columnas.

Existe una relación estrecha entre las facies de arena definidas, la geometría de los bancos y la posición de las arenas en las secuencias observadas. Las arenas micáceas forman bancos de geometría tabular con estructura interna compuesta por trenes de ripples, estratificación cruzada de surco o laminación horizontal, Asimismo, constituyen los términos "fining-up" de secuencias canalizadas. Por su parte, las arenas cuarzo-feldespáticas pardo rojizas constituyen el núcleo de estas formas canalizadas y, en conjunto, son la única facies arenosa hacia el techo de la sucesión.

El área de Canteras del Cerro Granja, junto a la carretera de Torrejón a Loeches, presenta una magnífica exposición de los niveles arenosos de la Unidad Intermedia, niveles que pueden ser seguidos en completa continuidad a lo largo de más de dos kilómteros de frentes de cantera. La sección representada en la figura 2 constituye la sucesión más com- pleta que ha podido ser levantada en el área. La parte basal, formada por lutitas de tonos grises con algunos niveles sulfatados y carbonatos, sería equivalente al techo de la unidad de Arcillas de Alcalá antes citada, mientras que los niveles arenosos marcarían, en una posición más distal, la progradación de terrígenos sobre esas facies arcillosas. Cuatro tramos arenosos, con potencias de 3,1,4 y 1,5 metros de media, aparecen intercalados entre lutitas rojizas a grises desde la base hasta la parte alta de la sección. El techo de ésta se presenta profundamente erosionado por potentes depósitos de terraza.

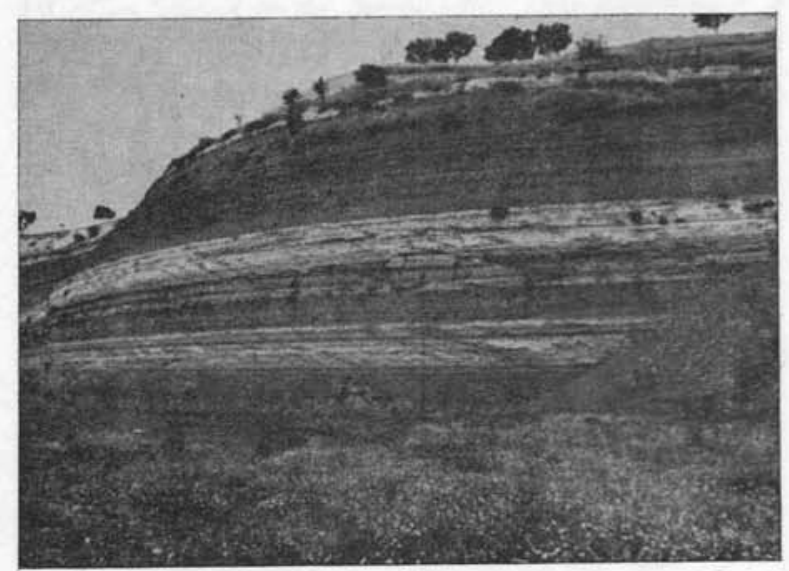

Fig. 4.-Frentes de cantera en la base del Cerro Granja. En tonos claros destacan los niveles de arenas micáceas, con geometría tabular y amplia continuidad lateral.

La particularidad de los niveles arenosos en las canteras del Cerro Granja reside en su carácter predominantemente micáceo (altos porcentajes de micas biotitas, en ocasiones hasta el $60 \%$ en número de granos, en todos los niveles), la geometría tabular de los tramos arenosos y, en relación con ello, la amplia continuidad lateral de todos los tramos (fig. 4). Los cambios observables entre las distintas secciones estudiadas consisten esencialmente en variaciones en la secuencialidad interna de los tramos y en la disminución de espesor de cada uno de ellos hacia el sur, tal como se expresa en la figura 2. El intervalo de tamaño de grano de las arenas en el conjunto de las secciones analizadas oscila entre tamaño de arena gruesa (centil $8 \mathrm{~mm}$., media $2.88 \mathrm{ph}$ ) a techo del tramo arenoso 3 y los tamaños aleurita finaarcilla representados en la mayor parte de los niveles.

La composición general de la mayor parte de las facies de areniscas responde a términos de arenas cuarzo-feldespáticas con porcentajes de micas que, como se ha señalado, son variables, generalmente siendo más frecuentes en las facies correspondientes a régimen de flujo más bajo. El contenido en minerales pesados en los diferentes niveles muestra, así mismo, un paralelismo con el carácter energético de las facies, siendo algo representativo (valores hasta $0.1 \%$ en peso) en los niveles de arenas más gruesas (con turmalina y apatito como más frecuentes) e inapreciables en los lechos de arenas finas y aleuritas.

Desde el punto de vista granulométrico los niveles de arenas presentan como valores más frecuentes: Media $=3.3$ phi, Desviación típica $=0.65$ y valores de 725 micras y 125 micras para centil y mediana respectivamente. El conjunto de las distribuciones representadas en papel probabilístico muestran una buena distribución de tres poblaciones lognormales, cuyos puntos de truncación tienden a situarse entre 1 y 2 phi para el de truncación a gruesos (C. T.); y entre 2 y 3.25 phi para el de truncación a finos (F. T.). Como tendencia general resalta la importancia dentro de las dis- 


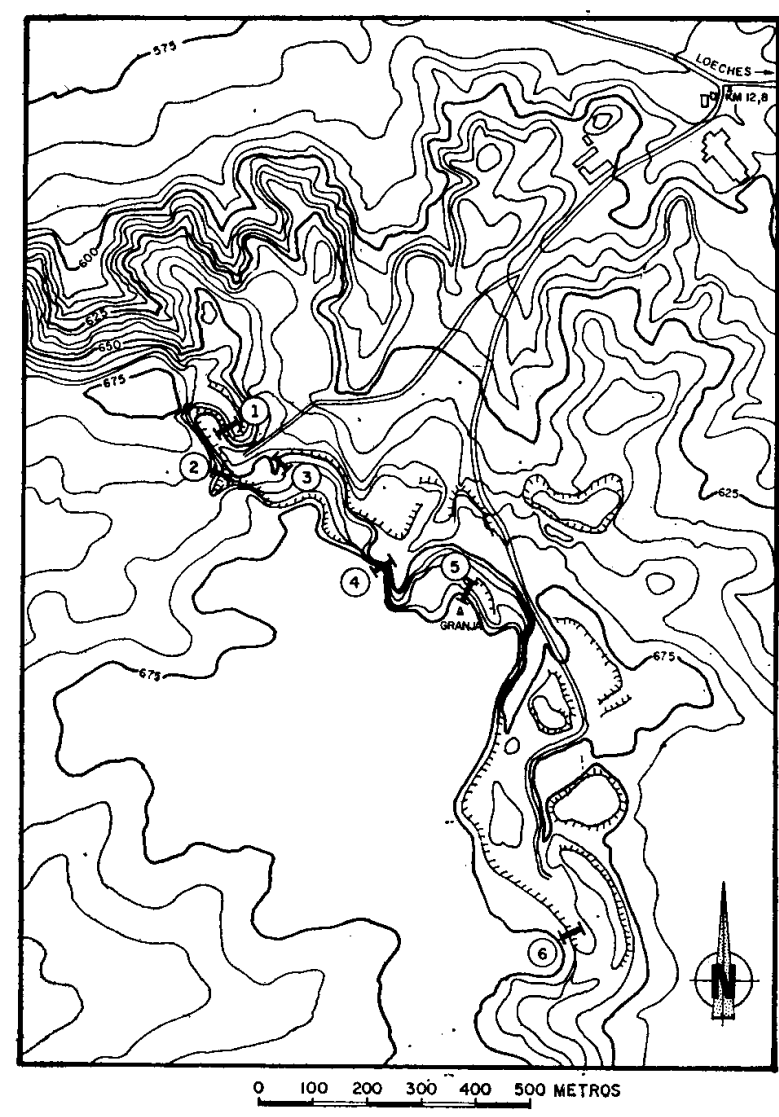

Fig. 5.-Situación de las secciones estudiadas en el área de Canteras de la Granja.

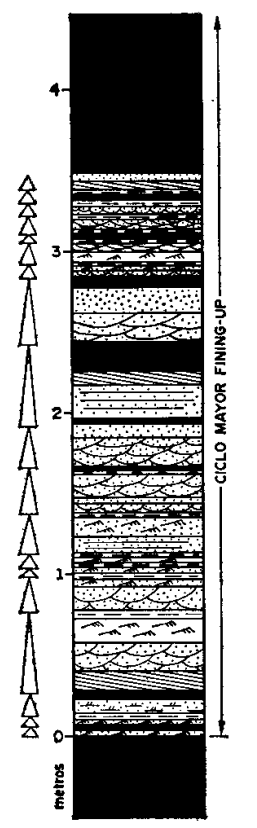

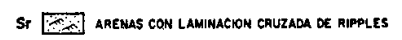

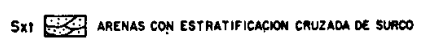

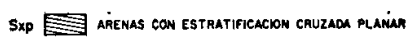

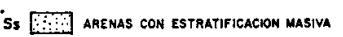

Sh arenas con estratifreacion planua

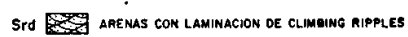

Mn

Ms $D$ aleuritas Y apcillas Masivas

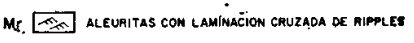

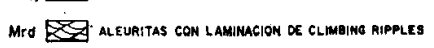

Fig. 6.-Ordenación vertical de facies arenosas y lutíticas en un ciclo mayor de las secciones de Canteras de la Granja. tribuciones de la población saltación (Visher, 1969). La representación CM (Centil-Mediana) (Passega, 1964) de los valores obtenidos en el conjunto de las muestras indica un transporte fluido de baja viscosidad y baja energía, predominando el transporte en suspensión gradada y saltación sobre el transporte en sólido y suspensión uniforme.

Dadas las excelentes características de afloramiento se ha podido proceder a un análisis sedimentológico en detalle de la sucesión, para lo cual se han levantado seis secciones seriadas a lo largo de los frentes de cantera (fig. 5). A partir de este análisis se han establecido, en primer lugar, un total de 10 litofacies (fig. 6) definidas por su granulometría y estructuras deposicionales. También, se han evaluado las pautas de ordenación de estas litofacies en la secuencia general en base al conjunto de los tránsitos verticales entre unas y otras, definiendo simultáneamente las rupturas de sedimentación presentes (contactos erosivos, criterios de estabilización a techo de secuencias: bioturbación y/o edafización). Se establecen así las transiciones binarias más frecuentes entre litofacies (tabla I). Las transiciones que presentan un porcentaje de frecuencia superior al $2 \%$ son las siguientes: $\mathrm{Mr} \rightarrow \mathrm{Mh}, \quad \mathrm{Sr} \rightarrow \mathrm{Mh}, \mathrm{Ms} \rightarrow \mathrm{Mh}, \quad \mathrm{Sr} \rightarrow \mathrm{Mr}$, $\mathrm{Ss} \rightarrow \mathrm{Ms}, \quad \mathrm{Sr} \rightarrow \mathrm{Ms}$ y $\mathrm{Mr} \rightarrow \mathrm{Ms}$.

TABla I

Transición de Facies para el total de las secciones

\begin{tabular}{|c|c|c|c|c|c|}
\hline $\begin{array}{c}\text { Transición } \\
\text { de } \\
\text { Facies }\end{array}$ & f. & $\%$ & $\begin{array}{c}\text { Transición } \\
\text { de } \\
\text { Facies }\end{array}$ & f. & $\%$ \\
\hline $\mathbf{M r} \rightarrow \mathbf{M h}$ & 84 & 22.35 & Sh $\rightarrow$ Sxp & 2 & 0.53 \\
\hline $\mathrm{Sr} \rightarrow \mathrm{Mh}$ & 49 & 13.03 & $\mathrm{Sh} \rightarrow \mathrm{Ss}$ & 2 & 0.53 \\
\hline $\mathrm{Ms} \rightarrow \mathrm{Mh}$ & 32 & 8.51 & $\mathrm{Sh} \rightarrow \mathrm{Mh}$ & 2 & 0.53 \\
\hline $\mathbf{M h} \rightarrow \mathbf{M s}$ & 28 & 7.45 & $\mathrm{Ss} \rightarrow \mathrm{Mr}$ & 2 & 0.53 \\
\hline $\mathrm{Sr} \rightarrow \mathrm{Mr}$ & 27 & 7.19 & $\mathbf{M r} \rightarrow \mathbf{S s}$ & 2 & 0.53 \\
\hline $\mathrm{Ss} \rightarrow \mathrm{Ms}$ & 26 & 6.91 & $\mathrm{Mr} \rightarrow \mathrm{Mrd}$ & 2 & 0.53 \\
\hline $\mathrm{Sr} \rightarrow \mathrm{Ms}$ & 19 & 5.05 & $\mathrm{Mrd} \rightarrow \mathrm{Sr}$ & 2 & 0.53 \\
\hline $\mathrm{Mr} \rightarrow \mathrm{Ms}$ & 15 & 3.99 & $\mathrm{Sh} \rightarrow \mathrm{Ms}$ & 1 & 0.26 \\
\hline $\mathrm{Sxt} \rightarrow \mathrm{Sr}$ & 12 & 3.19 & Sxt $\rightarrow$ Mrd & 1 & 0.26 \\
\hline $\mathrm{Sxt} \rightarrow \mathbf{M r}$ & 8 & 2.12 & Sxp $\rightarrow$ Mrd & 1 & 0.26 \\
\hline Ss $\rightarrow$ Mh & 8 & 2.12 & $\mathbf{S x p} \rightarrow \mathbf{M h}$ & $i$ & 0.26 \\
\hline $\mathrm{Sxt} \rightarrow \mathrm{Ss}$ & 7 & 1.86 & $\mathrm{Sr} \rightarrow \mathrm{Mrd}$ & 1 & 0.26 \\
\hline $\mathrm{Sr} \rightarrow \mathrm{Ss}$ & 7 & 1.86 & Srd $\rightarrow$ Ss & 1 & 0.26 \\
\hline $\mathbf{S h} \rightarrow$ Sxt & 4 & 1.06 & Srd $\rightarrow$ Mr & 1 & 0.26 \\
\hline $\mathrm{Sxt} \rightarrow \mathrm{Sh}$ & 4 & 1.06 & Srd $\rightarrow$ Mrd & 1 & 0.26 \\
\hline Sxt $\rightarrow$ Mh & 4 & 1.06 & $\mathrm{Ss} \rightarrow \mathrm{Sh}$ & 1 & 0.26 \\
\hline $\mathrm{Sh} \rightarrow \mathrm{Sr}$ & 3 & 0.8 & $\mathrm{Mrd} \rightarrow \mathrm{Srd}$ & 1 & 0.26 \\
\hline $\mathbf{S h} \rightarrow \mathbf{M r}$ & 3 & 0.8 & $\mathbf{M r d} \rightarrow \mathbf{M r}$ & 1 & 0.26 \\
\hline $\mathrm{Srd} \rightarrow \mathrm{Mr}$ & 3 & 0.8 & $\mathbf{M r d} \rightarrow \mathbf{M h}$ & 1 & 0.26 \\
\hline $\mathrm{Sxt} \rightarrow \mathrm{Ms}$ & 3 & 0.8 & & & \\
\hline $\mathbf{S x p} \rightarrow \mathbf{S x}$ & 2 & 0.53 & & 376 & 100 \\
\hline Sxp $\rightarrow$ Ss & 2 & 0.53 & & & \\
\hline
\end{tabular}

Resalta como rasgo general el carácter granodecreciente (ciclos fining-up) de estas transiciones, lo que sirve de base para el establecimiento de unidades gradadas positivas $(\mathrm{Hu}-$ bert y Hyde, 1982) compuestas por la superposición de dos o más facies. Los valores de probabilidad de las transiciones a partir del conjunto de las secciones analizadas se expresan en la matriz de síntesis de la figura 7 .

La acreción vertical del depósito en base a la repetición de estas unidades gradadas, junto con la amplia extensión lateral de los niveles y el carácter planar o muy suavemente erosivo de las bases, sugiere que la sedimentación tuvo lugar de acuerdo con un modelo de flujos no confinados, de amplia extensión lateral, por tanto no canalizados. La superposición de estructuras en las unidades gradadas sugiere un mecanismo de depósito por desaceleración del flujo (Banerjee, 1977) en las sucesivas arroyadas en lámina ("sheet 
floods"). Un ejemplo de estructuras características de desaceleración de flujo viene representado por el apilamiento de "climbing ripples", tal como se muestra en la figura 8. En conjunto, los niveles arenosos del área del Cerro Granja se interpretan como depósitos de flujo en lámina extendidos sobre sedimentos arcillosos de ambiente lacustre muy somero que episódicamente quedaron expuestos como áreas de "mud-flats". Este ámbito lacustre aparece más definido hacia el sur y sureste (zona de Loeches o Campo Real).

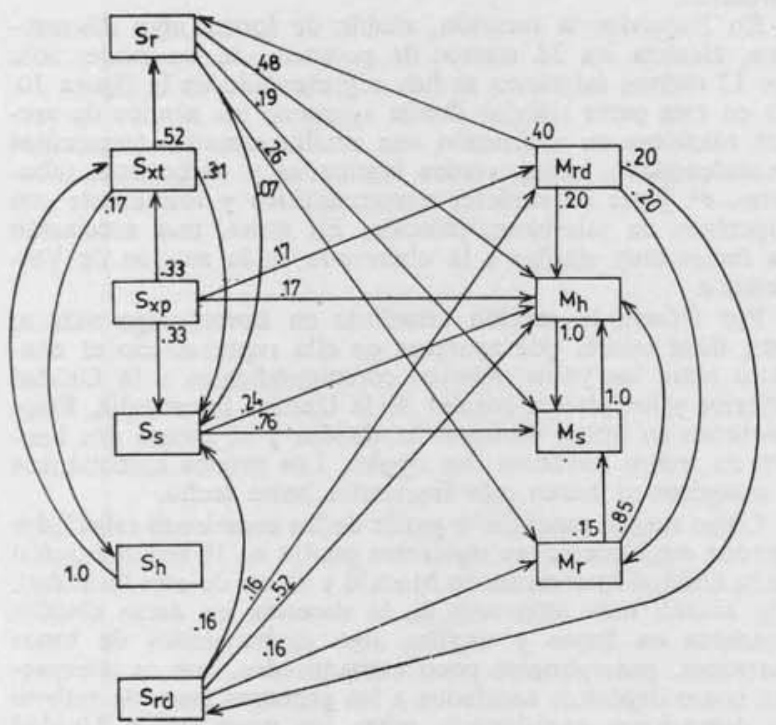

Fig. 7.-Esquema probabilístico del conjunto de las transiciones de facies arenosas y lutíticas en las secciones estudiadas en las Canteras de la Granja.

Las evidencias del carácter somero de esta asociación de facies son, junto con la interpretación secuencial antes señalada, las siguientes:

- Carácter esencialmente masivo de los depósitos arcillosos, con cambios en la tonalidad que son interpretados en relación con oscilaciones de la tabla de agua.

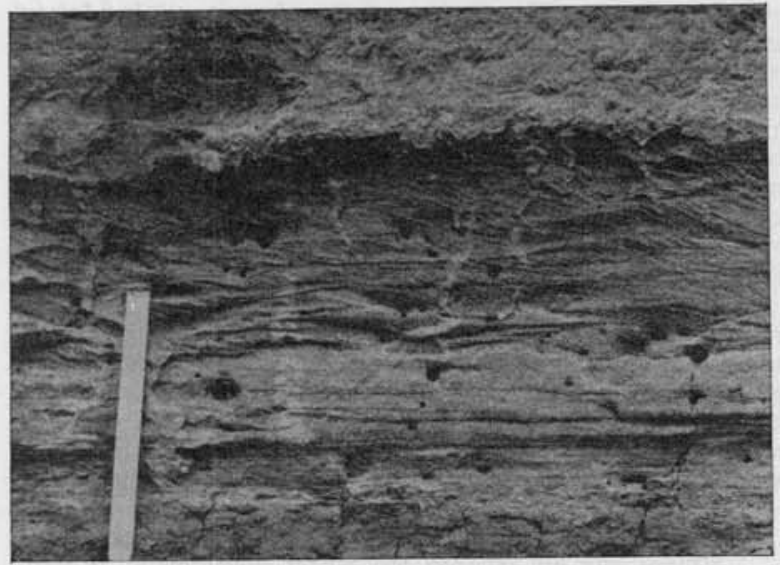

Fig. 8.-Facies de arenas micáceas con laminación de climbing ripples. Canteras de la Granja.
- Desarrollo intenso de bioturbación por raíces (rizolitos) a techo de muchas de las secuencias.

- Huellas de pisadas de aves en algunos niveles.

Frente a ello son muy escasas otros tipos de evidencias de exposición subaérea continuàda tales como grietas de desecación netas o ripples de adhesión. Los niveles con grietas de desecación son, en efecto, difícilmente observab.es, aunque en parte estas evidencias de desecación pueden estar representadas por lámınas arcillosas onduladas ("upcuried"), así como por la frecuencia algo frecuente de cantos blandos con morfología de "chips" lutíticos. Puede pensarse, por otra parte, que las condiciones durante la deposición de estas facies no fueron de una extrema aridez, sino de más bien de sequedad moderada con aguas de salinidad intermedia (Caivo et al., 1984).

Junto a estas características comunmente observables en los tramos 1, 2 y 4 de las canteras de Cerro Granja, el tramo 3 , sin embargo, presenta niveles canalizados de arenas medias a gruesas (fig, 2) que erosionan niveles de arenas y arcillas horizontalmente estratificadas. El carácter lateralmente discontinuo de estos canales puede ser comprobado por comparación entre las diferentes secciones. La amplitud de los canales suele alcanzar la decena de metros, mientras que su altura (espesor) varía entre 1 y 1,5 metros. El relleno de estos canales tiene un carácter multiepisódico y dentro de ellos destacan las formas de acreción lateral. Son muy frecuentes en estos niveles canalizados las estructuras de deformación, con desarrollo de morfologías variadas ("contorted bedding", "flumes", ...) (fig. 9). Estos cuerpos arenosos se interpretan como canales relacionados con cursos de moderada sinuosidad que erosionan depósitos "sheet flood" previos. Su relleno se realizó por medio de corrientes efímeras y episódicas tal como sugieren las sucesivas

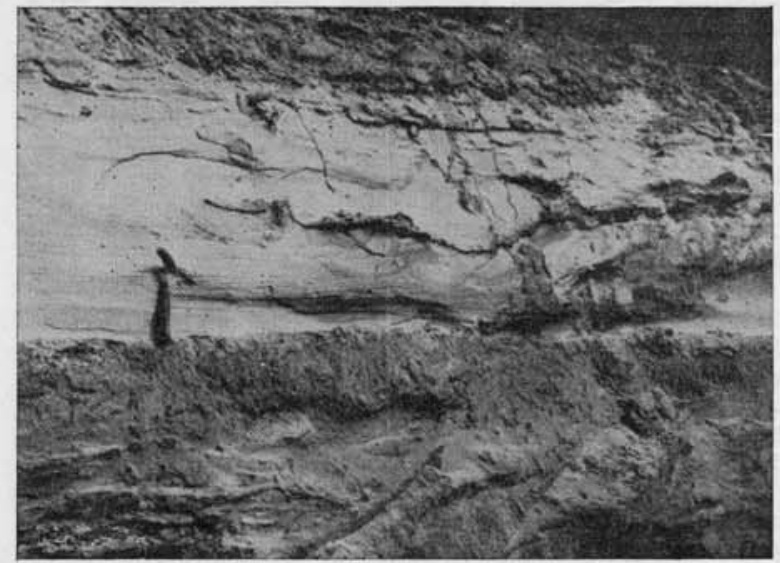

Fig. 9.-Detalle de un cuerpo arenoso canalizado correspondiente al tramo 3 de las secciones de Canteras de la Granja. Destacan en la parte central de la fotografía las estructuras debidas a escape de fluidos.

etapas de "scour and fill" y tapizados arcillosos dentro de estos canales. Como se ha indicado anteriormente, la granulometría de arenas en esta facies es más gruesa, de carácter cuarzo-feldespático, y mejor lavadas y seleccionadas. El porcentaje en micas es aquí notablemente inferior, destacando tan solo en algunas láminas dentro de ripples y a techo de dunas.

La asociación de facies arenosas y lutíticas del Cerro Granja const tuye la evolución distal de los niveles observados en la sección de Alcalá de Henares. Esta evolución viene marcada por la disminución entre ambos puntos del 
porcentaje relativo de arenas, el predominio de facies de arenas micáceas (más finas) frente a facies de litarenitas pardas, y la disminución de formas canalizadas frente a depósitos de "sheet-flood" y fangos depositados bajo lámina de agua semi-permanente. Esta evolución es asimilable al tránsito entre secuencia media y secuencia distal propuesto por Tunbridge (1984) dentro de un sistema de llanura aluvial-playa. Las direcciones de paleocorriente tomadas en ambas secciones indican un sentido SW o SSW, acorde con la polaridad de bandas de facies inicialmente observada.

\section{Sector Madrid-Esquivias}

La distribución y características de los depósitos correspondientes a la Unidad Intermedia del Mioceno en el área de Madrid han sido estudiados en bastante detalle por Alberdi et al. (1983), Calvo et al. (1984) y Hoyos et al. (1985). Se distinguen tres conjuntos de facies (detríticas, intermedias y palustres-lacustres) que representan la evolución lateral de facies desde el borde granítico hacia zonas centrales de la cuenca. Una distribución semejante se encuentra, en sentido transversal, a lo largo de toda la franja paralela al río Jarama desde el sur de Madrid hasta la provincia de Toledo (Carro y Capote, 1968; Vegas et al., 1975). Un estudio estratigráfico detallado fue realizado por Alía (1960) en la comarca de La Sagra.

El límite inferior de la Unidad Intermedia viene bien marcado a lo largo de los farallones de la margen izquierda del Jarama por la superposición neta de depósitos carbonáticos en facies palustres-lacustres (Facies Blanca de Alía, 1960) sobre sedimentos yesíferos masivos. Este límite suele venir marcado por arenas micáceas y lutitas sobre yesos a la altura de la carretera nacional IV. Más hacia el oeste la determinación de este límite es dudosa por la falta de afloramientos y por estar compuestas, tanto la Unidad Intermedia como la Únidad Inferior, por facies terrígenas. Localmente se observan acomodaciones con morfología sinclinal de los depósitos carbonatados o lutíticos de la Unidad Intermedia a huecos debidos a disolución (karstificación) en los yesos, pliegues que fueron ya señalados por autores antiguos (Royo Gómez, 1923; Hernández Pacheco, 1962) y que han sido revisadas más recientemente (Alberdi et al., 1983; Calvo et al., 1984) relacionándolos con procesos de karstificación tanto neógenos como cuaternarios.

La distribución de arenas micáceas en este ámbito aparece relegada esencialmente a la subunidad de arcillas verdes y arenas micáceas dentro de la Facies de Transición representadas en la figura 1. Señalaremos así mismo que algunos de estos niveles arenosos se han cortado a profundidades próximas a los 100 metros en sondeos efectuados en el área de Madrid (Calvo y García Yaglie, 1985).

El análisis sedimentológico de arenas en este sector se ha realizado en base al reconocimiento detallado de siete secciones situadas entre la localidad de Pinto, al norte, y la localidad de Borox como punto más meridional (fig. 10). De éstas, las secciones 3 y 5 corresponden a la evolución lateral hacia facies más distales de las sucesiones 2 y 4 , respectivamente. Además de ello se integran las observaciones y resultados obtenidos en el área de Madrid (Calvo et al., 1984) dada la similitud de procesos deposicionales y procedencia que la Unidad Intermedia presenta en dicha área.

La columna levantada en el camino del vertedero de Pinto (Pozo Seco, fig. 10) presenta una base predominantemente lutítica con bancos carbonáticos finos mientras que hacia techo se incrementan los niveles de arenas micáceas alternando con carbonatos tableados. La columna analizada en el kilometro 1,5 de la carretera de Pinto a San Martín de la Vega está constituida por margas, calizas de aspecto estromatolítico y un nivel relativamente ancho de arenas micáceas. Son frecuentes en esta sección los rasgos de edafización, con desarrollo de niveles de carbonatos vadosos. Más hacia el este esta serie se convierte en una sucesión monó- tona de carbonatos lacustres (Serie de El Rincón) que presenta en la base algunos niveles de yesoarenitas.

Esta misma tendencia se observa al comparar la sección de Valdemoro con la levantada algo más al este, en El Portillo. La columna de Valdemoro consiste en niveles de arenas micáceas y lutitas con carbonatos finamente tableados que contienen lentículas de yeso y ocasionalmente presentan superficies de microkarstificación. Hacia el este el predominio es de bancos carbonáticos con intercalaciones, menos espesas y más frecuentes hacia la base, de arenas micáceas.

En Esquivias la sucesión, visible de forma algo discontinua, alcanza los 32 metros de potencia, de los cuales sólo los 13 metros inferiores se han representado en la figura 10. Es en esta parte inferior donde aparecen los niveles de arenas micáceas en asociación con arcillas rosadas (esmectitas desordenadas), lutitas verdes laminadas y carbonatos tabulares, en parte de carácter estromatolítico y localmente con superfices de microkarstificación. En suma, una asociación de facies muy similar a la observada en la sección de Valdemoro.

Por último, la sección estudiada en Borox, algo más al este, tiene interés por aparecer en ella representado el contacto entre los yesos masivos correspondientes a la Unidad Inferior y los niveles basales de la Unidad Intermedia. Estos consisten en lutitas verdosas laminadas y al menos dos bancos de arenas micáceas con ripples. Los niveles carbonáticos y margosos se hacen más frecuentes hacia techo.

Como rasgos generales a partir de las sucesiones estudiadas pueden establecerse las siguientes pautas en la sedimentación de la Unidad Intermedia en Madrid y al sur de esta localidad. Los niveles más inferiores de la sucesión en áreas distales consisten en limos y arcillas algo carbonatados de tonos marrones, generalmente poco estructurados, qua se interpretan como depósitos asociados a las primeras fases de relleno de depresiones exokársticas sobre los yesos de la Unidad Inferior (Calvo et al., 1984). Así mismo, se sitúan en esta parte basal de la sucesión niveles de yesoarenitas laminadas (ej., sección de El Rincón) procedentes del desmantelamiento de los yesos infrayacentes (Megías et al., 1982). El espesor de estos yesos detríticos es variable según los puntos, pudiendo alcanzar algo más de la decena de metros. En posiciones algo más hacia el oeste el límite entre la Unidad Intermedia e Inferior viene marcado más netamente por la superposición de niveles terrígenos lutíticos y arenosos sobre los yesos.

El cambio de facies en sentido oeste-este en el sector meridional de Madrid y aproximadamente norte-sur en este área queda definido por secuencias de lutitas, arenas micáceas y algunos carbonatos que evolucionan lateralmente a secuencias predominantemente carbonatadas con niveles terrigenos muy subordinados. En el otro extremo de este cambio lateral de facies, al transición entre lutitas verdes y arenas micáceas con los depósitos arcósicos más gruesos hacia el oeste y norte es comúnmente difícil de observar por la falta de afloramientos. La sucesión aflorante en el cerro Cantueña, próximo a Fuenlabrada, permite observar tan sólo en vertical esta transición desde lutitas verdes a arcillas pardas arenosas con sepiolitas y sílex. En sentido transversal esta transición se presenta mejor definida en los farallones de Paracuellos del Jarama (Alonso, Calvo y García del Cura, en preparación).

Los niveles de arenas micáceas reconocidos en todas las secciones levantadas en este área tienen en común el pequeño espesor de los bancos, que en pocas ocasiones superan un metro de potencia. Salvo algunos niveles arenosos con alta proporción de arcilla, estructuración interna groseramento laminada y geometría tabular, los bancos arenosos exhiben generalmente los siguientes rasgos sedimentológicos:

- Cuerpos canalizados con base netamento erosiva, con alturas que no exceden los 50-60 centímetros. Presentan estructura granodecreciente a techo y estratificación cruzada planar a tangencial que evoluciona a techo a estratificación cruzada de surco y trenes de ripples. 

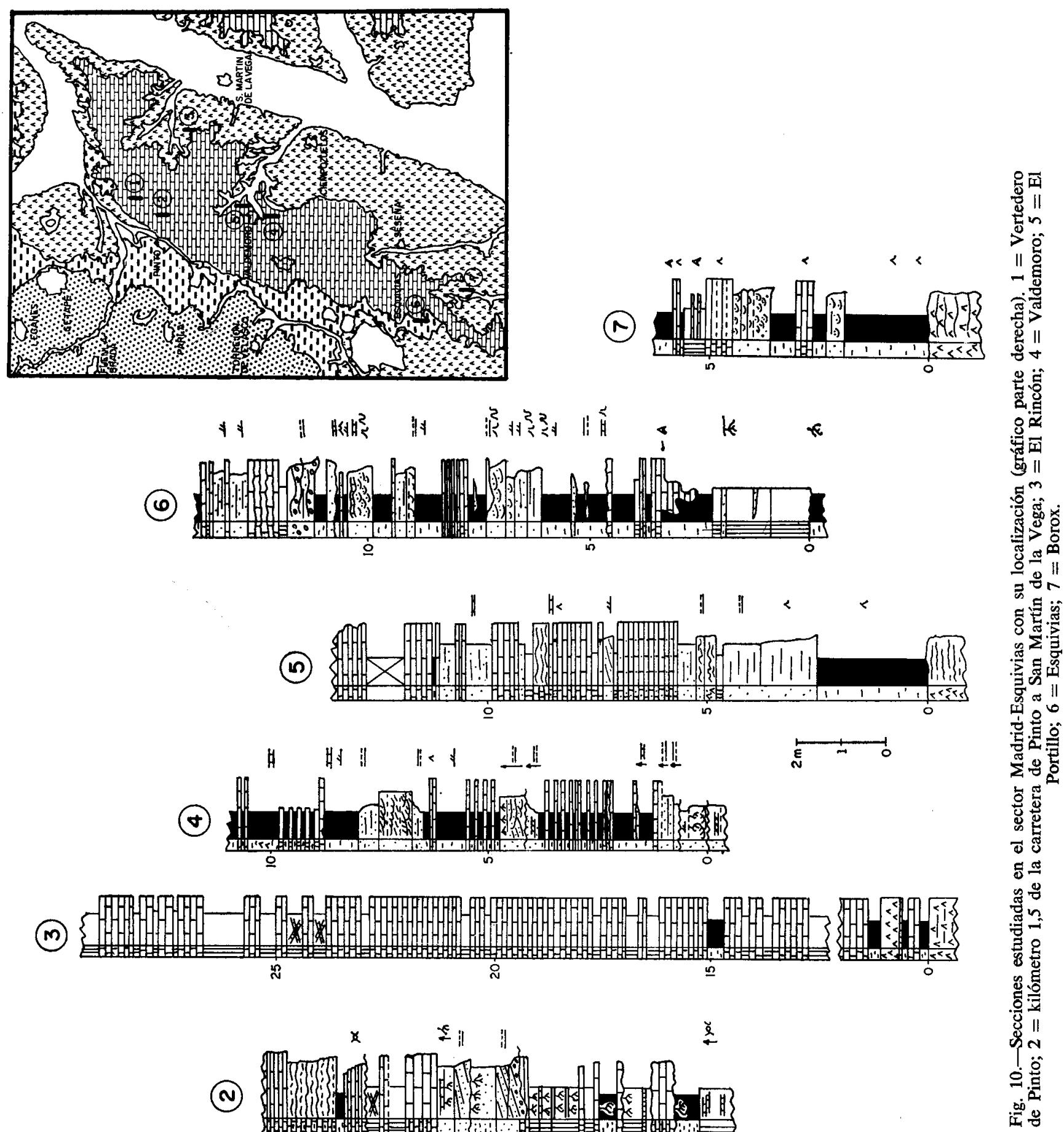

(1)
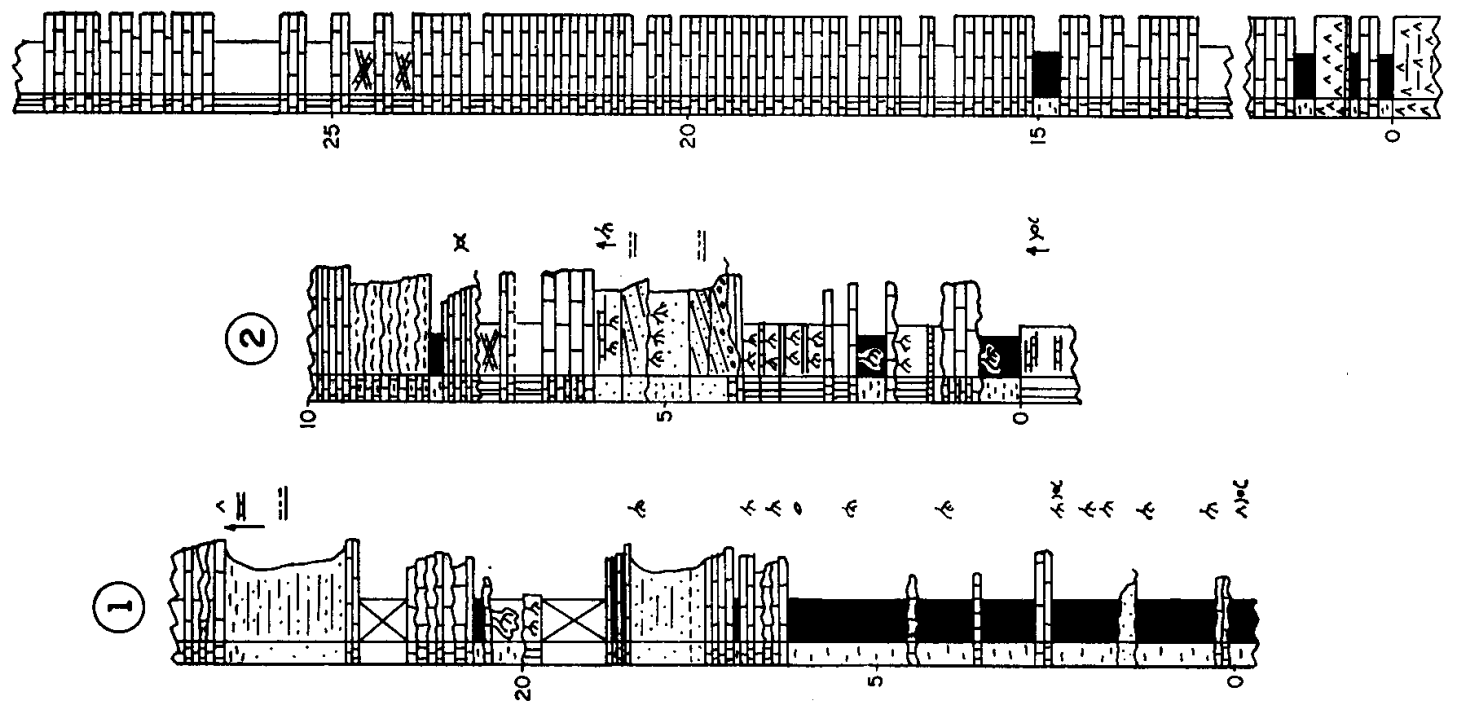
En algunos casos se observan "scour-and-fills" dentro de los bancos. Ejemplos de estas arenas pueden verse en las secciones 2 (Ctra. Pinto-San Martín de la Vega, fig. 11) y 4 (Valdemoro).

- Cuerpos tabulares con base plana o muy escasamente erosiva, con estructura interna mostrando una tendencia granodecreciente, compuestos por apilamientos de lechos arenosos con estratificación cruzada planar y de surco, arenas finas con laminación de ripples y, localmente, con pasadas de arenas masivas.

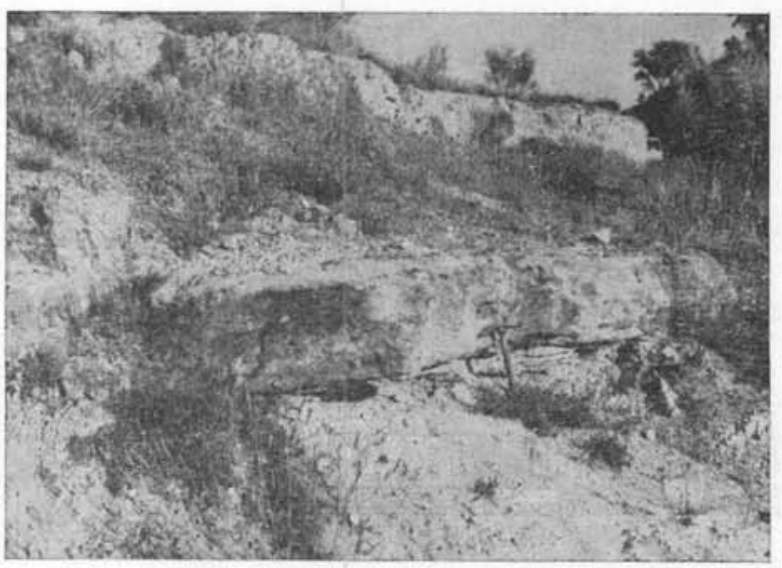

Fig. 11.-Arenas micáceas canalizadas. Carretera de Pinto a San Martín de la Vega.

En uno y otro caso las arenas micáceas aparecen asociadas con lutitas y carbonatos. Las lutitas presentan comúnmente tonalidades verdosas y su composición general es de esmectitas magnesianas con proporciones subordinadas de illitas trioctaédricas y, ocasionalmente, algo de caolinita. La presencia de sepiolita es más notable en las zonas de tránsito de estas facies verdes a las arcosas (facies de orla de abanico) (Megías et al., 1982; Calvo et al., 1984). Una litofacies de lutitas características en muchas secciones es la de arcillas rosadas de carácter grumoso cuya composición es similar a la de las lutitas verdes, pero con esmectitas magnesianas que se caracterizan por su total falta de ordenación. Se interpretan como producto de alteración pedológica de las lutitas verdes, dada su común disposición en secuencias lutitas verdes-arcillas rosadas-carbonatos vadosos (sección 2 entre Pinto y San Martín de la Vega; área de Madrid; etc. ...). En cuanto a los carbonatos, aparte de los niveles de carácter vadoso señalados, se han reconocido facies de carácter tableado-estromatolítico, niveles de calizas palustres (techos de secuencias arenas micáceas-arcillosas) y bancos de carácter lacustre somero más neto (micritas homogéneas con escasos ostrácodos) en las partes más distales. Tan sólo se han observado niveles de biomicritas hacia techo de la Unidad Intermedia en Esquivias y La Marañosa.

Las asociaciones de facies descritas y la distribución de las distintas secciones permite caracterizar un ambiente de sedimentación transicional entre orlas de abanicos arcósicos, comúnmente edafizadas, y zonas lacustres de carácter somero. Los niveles de arenas micáceas ocupan una posición intermedia entre ambos sistemas deposicionales, derivándose como "filtrado" a partir de las arcosas. En unos casos las arenas constituyen el relleno de canales de sinuosidad moderada a baja que surcaron áreas altas de "mud flat" diseccionando perfiles de alteración edáfica. En otros las arenas micáceas se extendieron en forma de "sheet floods" alcanzando áreas de "mud-flats" carbonáticos (Eugster y Surdam,
1973; Smoot, 1983) como zonas más permanentemente cubiertas por agua, dando lugar en este caso a secuencias deltaicas de muy escaso desarrollo. En conjunto las oscilaciones del sistema lacustre somero desarrollado hacia el este y sur fueron muy frecuentes a lo largo de toda la deposición de la Unidad Intermedia en este área, tal como reflejan la escasa potencia y variabilidad de las litofacies aplicadas en cada una de las secciones.

Desde un punto de vista textural las arenas micáceas estudiadas en este sector presentan distribuciones granulométricas con subpoblaciones lognormales (Visher, 1969) bien definidas, cuyos puntos de truncación oscilan entre 0,5 y 2 phi para el punto de truncación a gruesos y entre 2 y 3 phi para la truncación a finos. Los valores más frecuentes para la media son de 2,9 phi y de 0,90 phi para la desviación estándard. Los centiles y medianas presentan valores de alrededor de 0,550 milímetros y 0,150 milímetros, respectivamente. La proporción de minerales pesados es muy baja, con porcentajes del $0,05 \%$ en peso sobre la muestra total. Aparte de las micas oscuras, el espectro de minerales pesados consiste en circón, turmanila y apatito y, como accesorios, hematites, distena, granate y moscovita. El conjunto de datos texturales señalado permite interpretar que el transporte de las arenas micáceas tuvo lugar en un fluido de baja viscosidad y estado de flujo bajo, predominando el transporte en saltación y suspensión gradada sobre el transporte en rólido y suspensión uniforme. La comparación entre estos datos texturales y los obtenidos a partir de arcosas distales, con las que se infiere una continuidad de depósito, se hará en el apartado posterior.

\section{Conclusiones sedimentológicas y paleogeográficas}

Como resultado del estudio de las facies transicionales de la Unidad Intermedia del Mioceno en el área situada al este y sur de Madrid se extrae como conclusión general la existencia de dos sistemas deposicionales mayores convergentes hacia el centro de cuenca. El primero de ellos corresponde al sistema de abanicos cuyas áreas fuente se localizan en los materiales de metamorfismo de bajo grado de la parte oriental del Sistema Central. La composición de estos abanicos es, sin embargo, predominantemente arcósica como resultado de la mezcla con aportes de materiales graníticos situados al oeste de la falla de la Berzosa (Hoyos et al., 1985), siendo integrados dentro de las denominadas Facies Uceda de Aguilar y Portero (1984). Según estos autores el contenido en fragmentos de roca metamórficos superaría raramente el $20 \%$ en estas facies, siendo la matriz de caracter ferralítico y, en menor grado, sericítico. En el área estudiada por nosotros se extienden tan sólo los depósitos distales correspondientes a estos sistemas de abanicos (Portero et al., 1984), observándose entre Alcalá de Henares y Torrejón de Ardoz la transición entre secuencias con predominio de canales arenosos (facies medias, en el sentido de Tunbridge, 1984) y sucesiones lutíticas con intercalaciones de depósitos «sheet-flood» arenosos (facies distales). Estos depósitos, constituidos exclusivamente por arenas micáceas, se expandieron sobre áreas fangosas con escasa lámina de agua o bien episódicamente expuestas. Se reconocen, en este sentido, al- 
gunas formas de canales efímeros que diseccionaron localmente y en sucesivos estadios («multistorey channels») los depósitos de flujo en lámina.

Las direcciones de paleocorrientes medidas en las facies canalizadas de Alcalá de Henares así como en los depósitos arenosos del Cerro Granja son fundamentalmente SSW (fig. 12). La evolución más distal de estas facies es hacia secuencias de lutitas y carbonatos de carácter palustre/lacustre somero en el área de Loeches o Campo Real, facies que resultan convergentes con las desarrolladas en las partes más distales del sistema deposicional instalado en el área de Madrid y zona meridional.

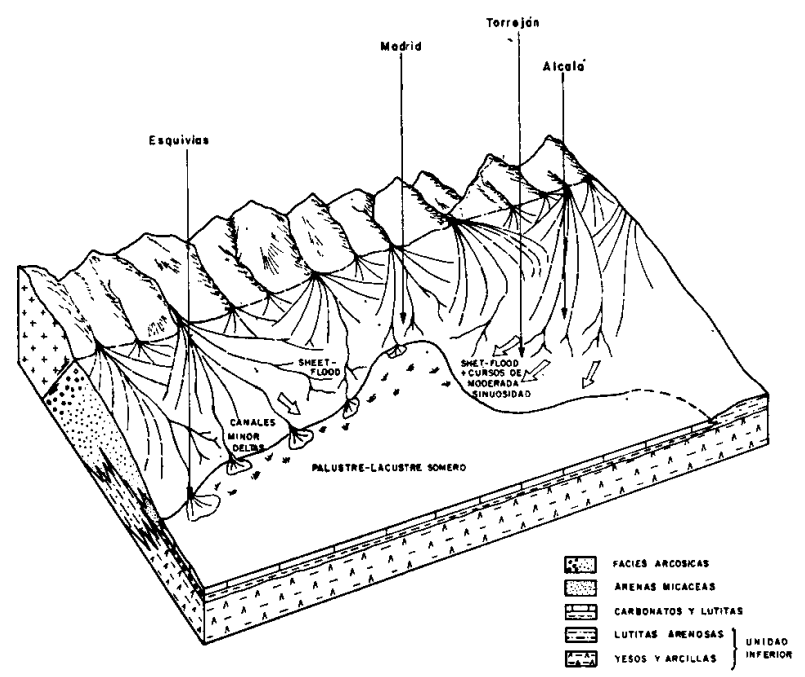

Fig. 12.-Esquema idealizado de la distribución de facies para la Unidad Intermedia del Mioceno entre Alcalá de Henares y Esquivias.

Este sistema deposicional aparece diferenciado del anterior por el carácter netamente arcósico de los depósitos que constituyen los abanicos aluviales, abastecidos predominantemente por los materiales granitoideos y metamórficos de alto grado del Sistema Central al oeste de la falla de la Berzosa. Estos sistemas de abanicos se desarrollaron progradando perpendicularmente al borde de la Sierra, dirección que se mantiene en los niveles de arenas micáceas instalados en la banda de facies transicionales hacia el centro de cuenca. Esta banda transicional aparece constituida por un intervalo de facies de abanico edafizada, facies palustres y/o ponds efímeros y facies lacustres someras más permanentes. Como rasgo general se infiere que la amplitud de esta banda debió ser algo más restringida que su equivalente en el sitema deposicional de Alcalá-Torrejón.

Tanto en uno como en otro sistema las arenas micáceas se presentan como un "concentrado» o derivado distal de las facies arenosas más gruesas con las que se asocian (arcosas/litarenitas en el área de Alcalá-Torrejón, arcosas s. s. en Madrid y zona sur). Las evidencias para esta conclusión son netas desde el punto de vista secuencial y de la distribución de facies. Así como se ha indicado, en la sección de Alcalá de Henares las arenas micáceas se presentan en el techo de secuencias granodecrecientes de relleno de canal o bien en niveles de arroyada en lámina («sheet flood») en la parte baja de la sección. En el Cerro Granja, dominado por estos niveles de «sheet flood», las arenas micáceas son la facies terrígena gruesa exclusiva salvo para algunos rellenos de canal más groseros y, de ahí, menos micáceos. En las arcosas de Madrid y sector meridional las evidencias más netas de esta derivación de las arenas micáceas vienen dadas por el aumento del porcentaje de biotitas en los lechos de arenas más finas así como en la continuidad geométrica de capas de arcosas y arenas progresivamente más micáceas (Secciones de Paracuellos del Jarama, Estación de O’Donnell, etc. ...). Los rasgos más característicos de esta litofacies de arenas micáceas (alta selección, tamaño de grano fino, alta ordenación estructural ...) se presentan en los depósitos debidos al apilamiento tras sucesivas fases de depósito por desaceleración de flujo, los cuales caracterizan los ámbitos más distales de los aparatos terrígenos.

Por último, la Unidad Intermedia del Mioceno en la zona estudiada presenta en conjunto e internamente un carácter progradante (Alberdi et al., 1983; Calvo et al., 1984; Aguilar y Portero, 1984). Ello se superpone a la pulsación penetrativa de terrígenos que ya ha sido descrita como uno de los criterios de definición del límite inferior de la Unidad. El carácter progradante de los depósitos de la Unidad Intermedia queda puesto de manifiesto con el análisis de las secciones de Alcalá de Henares (aumento de facies canalizadas en la vertical), Paracuellos del Jarama y Madrid (superposición de arcosas sobre facies lutíticas y carbonatadas, y de arcosas más gruesas sobre aquéllas) o secciones como la del Cerro Cantueña o Torrejón de Velasco, más al sur. La progradación de los depósitos se interpreta como relacionada con el progresivo levantamiento del Sistema Central a lo largo del Mioceno medio. Esta inestabilidad del borde durante la sedimentación de la Unidad Intermedia y la consiguiente sismicidad podría quedar reflejada, al menos en parte, por la abundancia de estructuras deformacionales observada en muchos niveles arenosos y lutíticos, hecho que también ha sido sugerido por Bustillo y Martín Escorza (1984) a partir de niveles carbonáticos de esta Unidad en otros puntos de la cuenca de Madrid. Además de este control tectónico algunas oscilaciones de carácter climático pueden ser invocadas para explicar la evolución vertical de la Unidad Intermedia. Desde el punto de vista paleoclimático tanto las faunas existentes (López Martínez y Morales, 1983) como los datos paleoedafológicos (Portero et $a l ., 1984)$ y las asociaciones de facies sugieren un clima seco, más bien cálido, con clara definición 
biestacional. Esta caracterización paleoclimática, que consideramos totalmente válida para una gran parte de la Unidad Intermedia, debió evolucionar, sin embargo, a unas condiciones en general más húmedas hacia el Aragoniense superior, tal como indica la mayor expansión de facies lacustres perennes y el mayor desarrollo de biotas (vegtación, ostrácodos, gasterópodos) en los niveles más altos de la secuencia (Calvo et al., 1984), e incluso los procesos de paleokarstificación bien patentes en algunas zonas de la cuenca, a techo de la Unidad Intermedia, previos a la instalación de los niveles terrígenos de la base de la Unidad Superior (Ordóñez et al., 1985).

\section{a) Distribuciones granulométricas}

Con carácter general, la representación gráfica en papel probabilístico de los intervalos de clase en escala $1 / 2$ phi, conduce a la definición de tres poblaciones lognormales en la práctica totalidad de las arenas micáceas analizadas. Los puntos de truncación se sitúan normalmente entre 1-2 phi para el punto de truncación gruesa y entre 2-3,2 para el de truncación a finos. La figura 13 muestra varios ejemplos de estas distribuciones en los niveles de arenas micáceas, pudiéndose observar diferencias bien patentes de las morfologías de estas distribuciones en
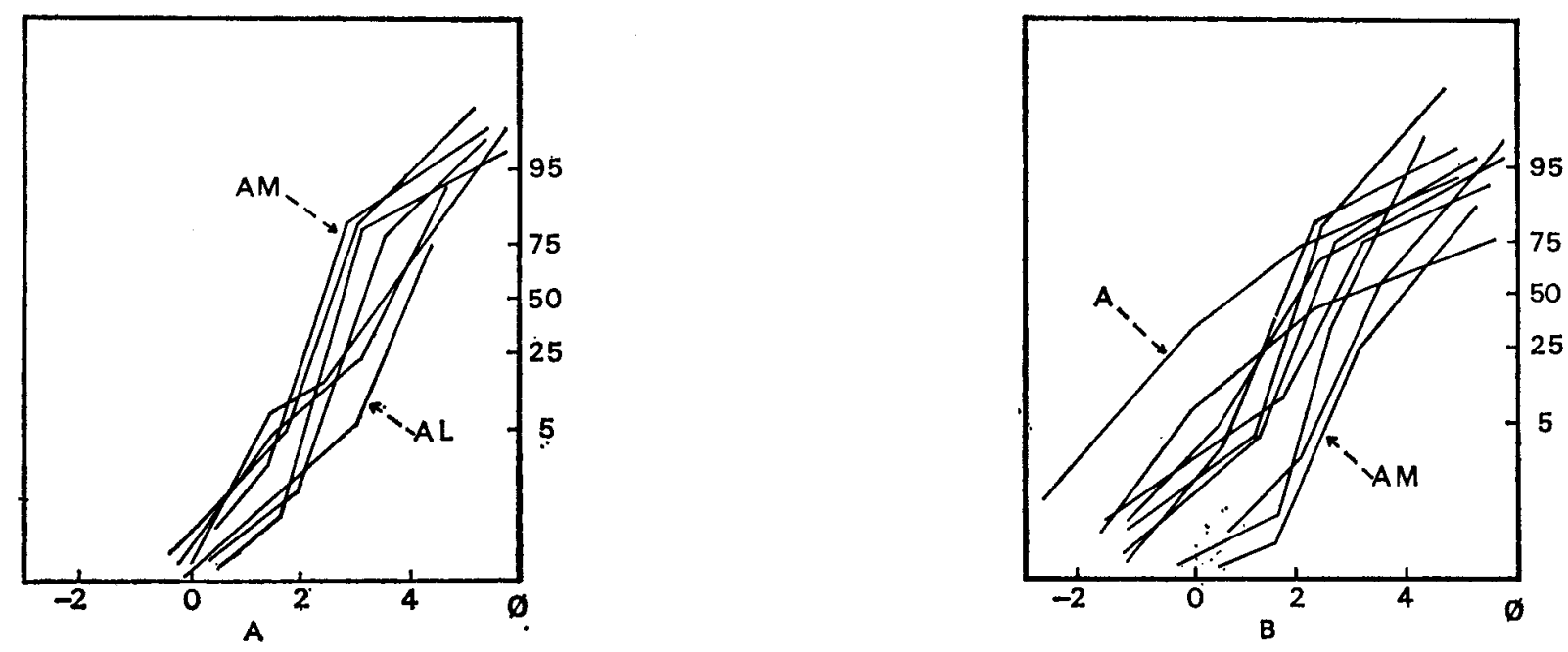

Fig. 13. - Comparación entre las distribuciones granulométricas de las distintas facies arenosas. A) Sector de Alcalá de Henares-Torrejón de Ardoz. B) Sector de Madrid-Esquivias. A. M. = arenas micáceas, A. L. = arcosas $/$ litarenitas, A. = $=$ arcosas.

\section{Consideraciones sobre la especificidad de las arenas micáceas}

La especificidad composicional y textural de los niveles de arenas micáceas está relacionada con el alto porcentaje en granos de micas (en ocasiones más del $20 \%$ en peso y hasta un $60 \%$ en número de granos) y con la morfología planar de las partículas. Estos aspectos requieren un análisis detenido, ya que el diferente comportamiento hidrodinámico de los granos puede introducir variaciones en la interpretación del medio deposicional en base a los elementos texturales.

En el presente trabajo se han estudiado más de 100 muestras de arenas micáceas. En base a este estudio se pueden establecer las siguientes consideraciones: relación con las presentadas por arenas arcósicolitoareníticas en el sector de Alcalá-Torrejón y con las de arcosas típicas en el sector de Madrid-Esquivias. Puede observarse la diferencia tanto en la posición de puntos de truncación como en la selección e incluso ausencia de alguna de las subpoblaciones entre unos materiales y otros.

La interpretación de las distribuciones granulométricas asume los postulados de diversos autores (Visher, 1969, 1980; Middleton, 1976), quienes sefialan la correlación entre estas subpoblaciones lognormales con los diferentes modos de transporte o selección hidráulica de los granos (rólido, saltación, suspensión). Las posibles variaciones a este modelo vienen determinadas en algunos casos por la naturaleza del área fuente y la rotura mecánica de los granos. Los resultados obtenidos en el análisis de 
las arenas micáceas muestran una alta contribución de la población saltación y una también importante contribución de la población suspensión. La población rólido aparece siempre escasamente representada.

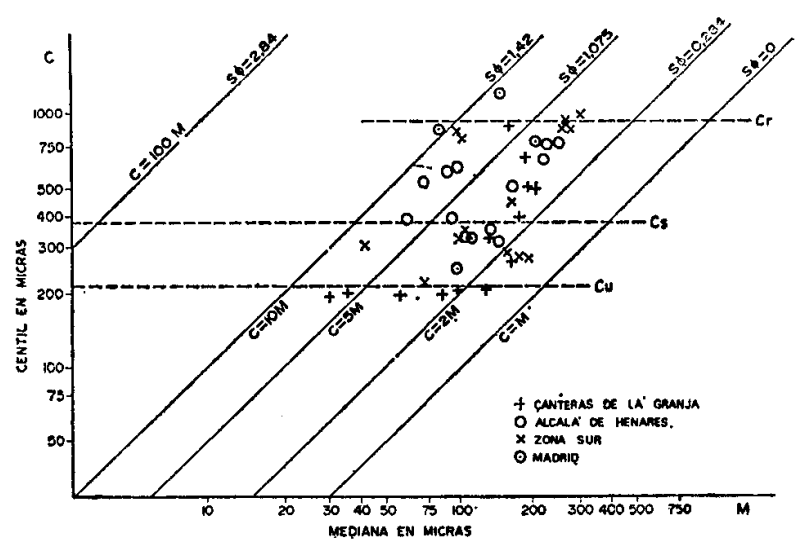

Fig. 14.- Representación Centil-Mediana de los datos clastométricos en el conjunto de los sectores estudiados.

\section{b) Representación Centil-Mediana (CM)}

La nube de puntos (fig. 14), correspondiente a los valores C y M (Passega, 1964) de las arenas micáceas permite concluir que las distintas fracciones en cada muestra han sido transportadas bajo diferentes formas, pero siempre dentro de los siguientes límites:

- Medio fluido de viscosidad baja a media.

- Saltación predominante sobre suspensión; la suspensión gradada predomina, asimismo, sobre la suspensión uniforme.

- La escasa importancia del transporte en rólido en estas arenas queda también reflejada de acuerdo con este modelo de análisis textural.

\section{c) Análisis Factorial}

Se ha construido una matriz inicial de datos a partir de 103 muestras de arenas micáceas. Las 11 variables tomadas corresponden a los porcentajes en peso retenidos en cada tamiz, desde dos milímetros a 0,062 milímetros. Como conclusión de este análisis se obtiene que a partir de tres factores de correlación principales, que explican el $80 \%$ de la varianza total, se distinguen netamente cuatro tipos de poblaciones clastométricas (fig. 15), las cuales corresponden a diferentes características de transporte (rólido, saltación, suspensión gradada y suspensión uniforme) con límites bien definidos entre sí. Dichos límites son aplicables, por tanto, a la separación de poblaciones en las muestras correspondientes a las facies detríticas transicionales (arenas micáceas) de la Unidad Intermedia del Mioceno en el sector de la cuenca de Madrid estudiado.

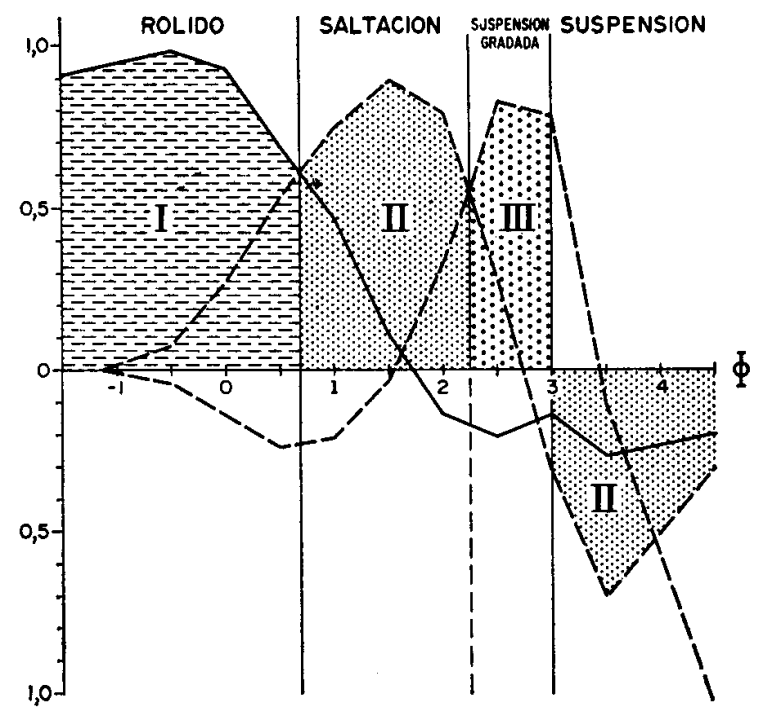

Fig. 15.-Representación final de los perfiles de peso obtenidos mediante Análisis Factorial. Explicación en el texto.

\section{d) Implicaciones hidrodinámicas y sedimentológicas derivadas del alto porcentaje en micas}

El comportamiento hidráulico de las micas es, por su forma planar, diferente al de los componentes detríticos con hábitos más equidimensionales (Tourtelot, 1968; Komar y Reymers, 1978; Doyle et al., 1983). Dado el alto porcentaje en micas que presentan las arenas estudiadas en este trabajo, la constatación anterior nos lleva a proponer la necesidad de una corrección en las distribuciones granulomé-

Tabla II

\begin{tabular}{llcc}
\hline mm. & Micas & Resto & Total \\
\hline 2 & & 0 & 0 \\
1.5 & & 0.20 & 0.20 \\
1 & & 0.70 & 0.70 \\
0.71 & 0 & 2.49 & 2.49 \\
0.5 & 0 & 9.23 & 9.23 \\
0.35 & 0.01 & 19.82 & 19.82 \\
0.25 & 0.03 & 21.46 & 21.49 \\
0.16 & 0.4 & 55.31 & 55.71 \\
0.125 & 1.5 & 15.65 & 17.45 \\
0.088 & 8.08 & 7.03 & 15.11 \\
0.062 & 3.97 & 1.67 & 5.64 \\
& 0.98 & & 0.98 \\
& 0.48 & & 0.48 \\
& 0.16 & & 0.16 \\
\hline
\end{tabular}


tricas obtenidas por técnicas estándard de tamizado y, de ahí, a una definición más ajustada de sus parámetros texturales.

El tratamiento realizado ha consistido en la separación magnética de las micas en cada fracción de tamaño retenida en los tamices obteniéndose así dos distribuciones distintas, una primera correspondiente a las micas y una segunda para el resto (tabla II). La distribución granulométrica definitiva se construye calculando el tamaño hidráulico equivalente de las micas, para lo que se parte de la ley de Stokes y del factor de corección de forma (Tourtelot, 1968). A modo de comprobación, este factor ha sido recalculado a partir del gráfico de equivalencia hidráulica elaborado por Doyle et al. (1983).

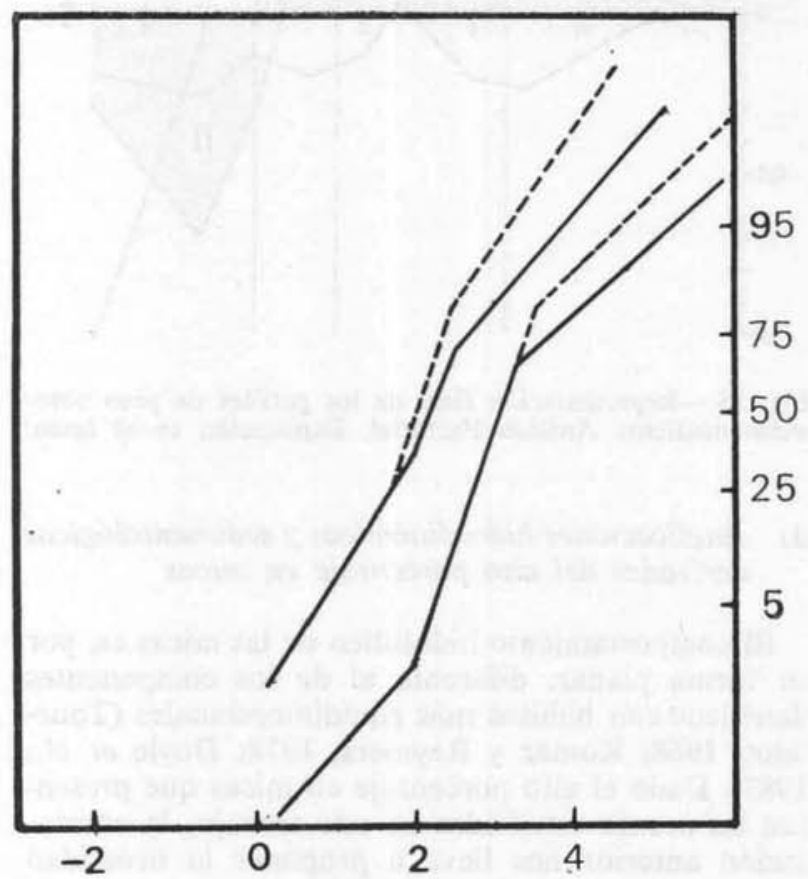

Fig. 16.-Comparación entre distribuciones de tamaño de arenas micáceas. El trazo continuo corresponde a la curva de distribución de tamaños tras la corrección efectuada teniendo en cuenta el tamaño hidráulico equivalente de las micas.

La conclusión obtenida a partir de este tratamiento de los datos es que la columna de frecuencia de las micas se desplaza 1,5 phi hacia finos con respecto del resto (fig. 16). El resultado es que las distribuciones corregidas se ajustan mejor a las poblaciones lognormales, siendo, además, más correctas desde un punto de vista hidrodinámico.

\section{e) Mineralogía}

La composición mineralógica de las arenas micáceas es, de forma resumida, la siguiente:
- Granos de cuarzo, esencialmente monocristalinos. Escaso cuarzo policristalino.

- Feldespatos, esencialmente de carácter potásico. Las plagioclasas se caracterizan por su bajo contenido en calcio. En general los feldespatos presentan cierta alteración a montmorillonita-illita.

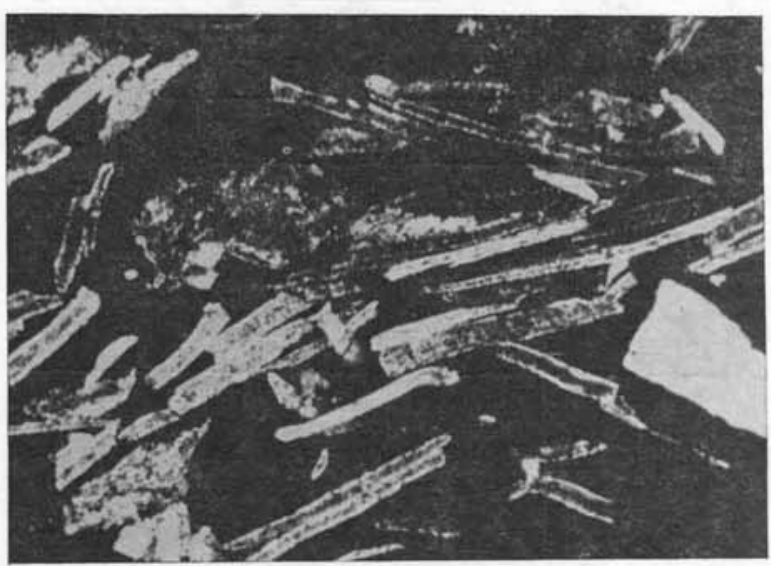

Fig. 17.-Granos de micas biotitas concentrados tras su separación magnética del conjunto de la muestra.

- Fragmentos de rocas metamórficas y/o graníticas.

- Micas oscuras en proporciones del 10 al $20 \%$ del total en peso y hasta el $60 \%$ o más en número de granos. Esta abundancia en micas oscuras se corresponde en general con los niveles arenosos más finos. El análisis detallado de la fracción micácea tras su separación magnenita, estudio petrográfico (fig. 17) y difracción de rayos $\mathrm{X}$, pone de manifiesto que estas micas oscuras son esencialmente biotitas. Algunos granos presentan cierta alteración a vermiculita y clorita. Señalaremos que la clorita como tal no aparece claramente definida en los difractogramas.

- Las moscovitas son siempre escasas y generalmente relegadas a las fraciones más gruesas.

- El contenido en minerales pesados es mínimo, con un espectro mineralógico reducido a los más resistentes.

Como conclusión, a partir de estos rasgos mayores en la composición mineralógica de las arenas micáceas, puede establecerse que éstas constituyen, como se deduce igualmente de las relaciones de facies, el derivado distal de depósitos arcósicos y arcósico/lita- 
reníticos en condiciones de flujo más bajo y transporte de menor viscosidad. Quedan en último extremo sin establecer las causas que dan lugar al brusco decrecimiento en el porcentaje de moscovitas en estas facies distales, en relación con los depósitos anteriormente señalados. Dicha cuestión exigiría un análisis detallado de la repartición relativa de los distintos tipos de micas tanto en los sedimentos terrígenos analizados como en las áreas fuente graníticas y metamórficas, lo cual queda fuera de los objetivos del presente trabajo.

\section{Agradecimientos}

Los autores expresan su agradecimiento al doctor $\mathbf{M}$. Hoyos y a don $F$. Junco por sus sugerencias durante la realización de este trabajo, así como por sus comentarios al manuscrito. Asimismo agradecemos la ayuda prestada por las doctoras M. A. García del Cura, C. López-Azcona y M. Doval en la determinación mineralógica mediante difracción de rayos $\mathrm{X}$. A don R. Fort por su asesoramiento en las técnicas de separación magnética y estudio de minerales pesados. A E. Alegre y J. M. Angulo por su desinteresada colaboración en la preparación del material fotográfico y delineación, respectivamente. El trabajo se incluye dentro del "Estudio sedimentodinámico y geoquímico de la zona sur y sureste de Madrid", integrado en el proyecto "Evolución geológica de la Meseta y su Margen Ibérico", financiado por C.A.Y.C.I.T. y el C.S.I.C.

\section{Bibliografia}

Aguilar, M. y Portero, J. M.

1984. Las arenitas de los abanicos aluviales terciarios del borde suboriental del Sistema Central, I Congreso Español de Geologîa, 3, 147-158.

AlBERDI, M. T., et al.

1983. Bioestratigraphie et evolution sedimentaire du Neogene continental de l'aire du Madrid. Abst. Inst. Coll. Mediterr. Nelogene Cont. Paleoenvir. and Paleoclimatic Evolution, 15-18.

ALÍA, M.

1960. Sobre la tectónica profunda de la fosa del Tajo. Notas y Com. I.G.M.E., 58, 125-162.

ALía, M., et al.

1973. Evolución geotectónica de la región de Ocaña (Toledo) durante el Neógeno y el Cuaternario. Bol. $R$. Soc. Esp. Hist. Nat., 71, 9-20.

BANERJEE, I.

1977. Experimental study on the effect of deceleration on the vertical sequence of sedimentary structures in silty sdiments. Jour. Sed. Petrol., 47, 771-783.

Bustillo, M. y Martín Escorza, C.

1984. Estructuras primarias y de deformación en rocas opalinas del Mioceno medio (Toledo). I Congreso Español de Geología, 1, 159-172, Segovia.

Calvo Sorando, J. P. y García Yagüe, A.

1985. Nuevos sondeos de investigación geológica en el área de Madrid. Estudios geol., 41, 25-317.

Calvo Sorando, J. P. et al.

1984. Resultados del estudio geológico a escala $1 / 25.000$ del término municipal de Madrid. Actas del Simposio sobre geotecnología del subsuelo de Madrid (en prensa).

Calvo Sorando, J. P.; Ordóñez, S.; Hoyos, M. y García Del CuRa, M. A.

1984. Caracterización sedimentológica de la Unidad Intermedia del Mioceno al sur de Madrid. Rev. Mat. Proc. Geol., 2, 145-176.

CAPOTE, R. Y Carro, $S$.

1968a. Mapa Geológico de España. Escala 1/50.000 (2.a serie). Explicación de la Hoja núm. 560 (Alcalá de Henarels). I.G.M.E.

1968b. Existencia de una red fluvial intramiocena en la depresión del Tajo. Estudios geol., 24, 91-97.

1968c. Mapa Geológico de España. Escala 1/50.000 (1.a serie, 2. ${ }^{a}$ edición). Explicación de la Hoja número 605 (Aranjuez). I.G.M.E.

Doyle, L. J.; Carder, K. L. y STeward, R. G.

1983. The hydraulic equivalence of mica. Jour. Sed. Petrol., 53 (2), 643-648.

Eugster, H. P. y Surdam, R. C.

1973. Depositional envinment of the Green River Formation of Wyoming: a preliminary report. Bull. Geol. Sac. Am., 84, 1115-1120.

García del Cura, M. A.

1979. Las sales sódicas, calcosódicas y magnésicas de la cuenca del Tajo. Fundación Juan March, serie universitaria, 39 págs.

Hernández Pacheco, F.

1962. Caracteres de los plegamientos del Neógeno de la Depresión del Tajo. Primer Coloquio Internacional sobre Obras Públicas en terrenos yesíferos. SGOP, Madrid, tema 6, 45-57.

Hoyos, M.; Junco, F.; Plaz, J. M.; Ramírez, A. y Rurz, J. 1985. Geología y Paleontología del área de Madrid. Publicaciones del C.S.I.C., 9-16.

HUderT, J. F. Y HYde, M. G.

1982. Sheet-flood deposits of graded beds and mudstones on an alluvial sandflat- playa system: Upper Triassic Blomidon redbeds, St Mary's Bay, Nova Scotia. Sedimentology, 29 (4), 457-474.

Junco, F. y Calvo Sorando, J. P.

1984. Cuenca de Madrid. In "Libro Homenaje a J. M. Ríos" (en prensa).

Komar, P. D. y Reimers, C. E.

1978. Grain shape effects on settling rates: Jour. Geol., 86, 193-209.

López Martínez, N. y Morales, J.

1983. Paleontología del Terciario de la cuenca de Madrid. En Mem. Est. Gelol. a escala 1/25.000 del Término Municipal de Madrid. Ayuntamiento de Madrid.

LóPEz VERa, F.

1975. Hidrogeología regional de la cuenca del rio Jarama en los alrededores de Madrid. Tesis Doctoral. Mem. I.G.M.E., vol. 91.

Megías, A. G.; Leguey, S. y Ordóñez, S.

1982. Interpretación tectosedimentaria de la génesis de fibrosos de la arcilla en series detríticas continentales (cuencas de Madrid y del Duero), España. Quinto Congreso Latinoamericano de Geología, Argentina, Actas II, 427-439. 
Megías, A. G.; Ordóñez, S.; Calvo, J. P. y Garcta del CURA, M. A.

1982. Sedimentos de flujo gravitacional yesíferos y facies asociadas en la cuenca neógena de Madrid (España). Quinto Congreso Latinoamericano de Gea logía, t. II, 311-328.

Middleton, G. V.

1976. Hidraulic interpretation of sand size distributions. J. Geol., 84, 405-426.

Ordóñez, S, et al.

1983. Contribución al conocimiento de la sedimentogénesis evaporítica en las cuencas neógenas de Madrid y del Duero en base a datos de isótopos establecidos. X Congr. Nac. Sed. Menorca, Resúmenes, 49-52.

Ordóñez, S.; García del Cura, M. A.; Hoyos, M. y Calvo, J. P.

1985. Middle Miocene Paleokarst in the Madrid Basin (Spain). A complex Karstic System. 6th. European Reg. Meet. I.A.S., Lleida, Abstracts, 624627.

Passega, R.

1964. Grain-size representation by CM patterns as a geological tool. Jour. Sed. Petrol., 34, 830-847.

Portero, J. M.; Olive, A. y AzNar, J. M.

1984. El Terciario del borde meridional del Guadarrama y Somosierra. Libro Homenaje a J. M. Ríos, tomo II (en prensa).

Portero, J. M. y Aznar, J. M.

1984. Evolución morfotectónica y sedimentación terciarias en el Sistema Central y cuencas limitrofes (Duero y Tajo). I Congreso Español de Geología, t. I, 285-300.

RiBA, 0.

1957. Ensayo sobre la distribución de las litofacies del Terciario continental de la cuenca del Tajo al oeste de la Sierra de Altomira. Cursillos y Conferencias Inst. Lucas Mallada, 3, 177 págs.

RoYo GómEz, J.

1923. El Mioceno de Vallecas (Madrid) y comarcas próximas. Asoc. Esp. Prog. Cienc., Congr. Salamanca, t. 6, secc. 4, 107-120.

1929. Memoria explicativa de la hoja 559 (Madrid). Mapa Geológico 1/50.000, I.G.M.E., 131 págs.

SAN José, M. A.

1975. Mapa Geológico de España 1/50.000, Hoja de Arganda (583), 2.a serie, I.G.M.E.

SмоOT, J. P.

1983. Depositional subenvironments in an arid closed basin; the Wilkins Peak Member of the Green River Formation (Eocene), Wyoming, U.S.A. Sedimentology, vol. 30 , núm. 6,801 .

Torres, T.; Junco, E.; Zapata, J. L. y Plaza, J. M.

1984. Similitud de los procesos sedimentarios del Neógeno en la cuenca del Tajo y en la Depresión Intermedia. I Congreso Español de Geologia, t. I, 285-300.

TOURTELOT, H. A.

1968. Hydraulic Equivalence of Grains of Quartz and Heavier Minerals, and Implications for the study of Placers. Geol. Survey Prof. Paper, 594-F, 13 págs.

TURNBridge, I. P.

1984. Facies Model for a sandy ephemeral stream and clay playa complex; the Middle Devonian Trentishoe Formation of North Devon, U. K. Sedimentology, vol. 31, núm. 5, 697.

Vegas, R.; Pérez González, A. y Miguez, F.

1975. Mapa Geológico de España 1/50.000, 2. ${ }^{a}$ serie, Hoja núm. 19-23, Getafe, I.G.M.E.

VillarRoya, F.

1983. Características litológicas del subsuelo de la zona Torrejón de Ardoz-Alcalá de Henares (Madrid). Tecniterrae, núm. 53, 72, Madrid.

VISHER, G.

1969. Grain-size distributions and depositional processes. Jour. Sed. Petrol., 39, 1074-1106.

1980. Grain-size frequency studies. In: The Enciclopedy of Sedimentology, R. Fairbridge (Ed.), 370-374.

Recibido el 28 de octubre de 1985 Aceptado el 26 de noviembre de 1985. 